\title{
Public wi-fi in Australian cities: are there lessons for 'smart city' government?
}

\author{
Ian McShane ${ }^{1}$ and Chris K Wilson ${ }^{1}$ \\ ${ }^{1}$ Centre for Urban Research, RMIT University
}

\begin{abstract}
Wireless communication is now integral to the social, economic and cultural life of cities and will become increasingly so as Internet of Things (IOT) technologies alter existing urban processes and generate entirely new ones. Although wireless connectivity engages almost all aspects of urban governance, management of the underpinning infrastructure is essentially a new field of activity for city governments. Telecommunications and spectrum management has always been a national policy domain and telecommunication infrastructure and services have been provided by the private sector over the past 25 years.
\end{abstract}

The rapid rollout of public wi-fi is the first substantive engagement of Australian city governments in wireless infrastructure policy and practice. Over the past five years, investment by state and municipal governments has yielded operational networks in capital city CBDs, many suburban centres and regional cities, and even some smaller towns. While investment rationales have focused on benefits that might accrue from providing communication services to citizens and tourists, city governments are beginning to appreciate the value that data derived from network users could have in the actual enterprise of governing. However, realising the potential of public wi-fi to inform smarter city government is not proving straightforward.

Drawing on field research, and legal and policy analysis, this paper discusses two barriers to public wifi informed smarter city ambitions: local authority procurement decisions and local human resource limitations. We argue that the combination of these factors has contributed to the privatisation of public wi-fi data and diminished the public value of local network investment.

Key words: public wi-fi; digital infrastructure; local government

\section{Introduction}

Local public wireless networks play an increasingly significant role in urban broadband provision and in urban management in Australia and elsewhere. In Australia, the past five years has seen the establishment of public wi-fi networks in almost all major cities and many smaller urban centres (Lambert et al., 2013; McShane et al., 2014; Wilson and McShane, 2017), as well as some remote settlements (Rennie et al., 2016). The Australian Competition and Consumer Commission (2016) and the Productivity Commission (2017) have recognised the important role such networks now play in the mix of communication services available to Australians. Telecommunication companies that once viewed public wi-fi as a competing service now consider it a means of relieving congestion on their own cellular networks as well as a commercial opportunity (exemplified by the rollout of the Telstra Air network) (MAV Technology, 2015, pp. 41-43). Recent reports suggest that public wi-fi is now accessed by around 5 million Australians (McShane et al., 2016; ACMA, 2016a) and plays a particularly significant role as "survival infrastructure" for the homeless and disadvantaged (Humphry, 2014), and for other population segments lacking local mobile connectivity options, such as tourists (Picco-Schwendener and Cantoni, 2015).

While city governments have commonly pointed to public wi-fi's role in providing broadband access to constituents and visitors as a smart city initiative, more recently they have recognised the opportunity for public wi-fi to play a role in smart city urban management. One such approach is to use public wi-fi as a base infrastructure to provide backhaul connectivity to control smart city Internet of Things (IoT) technologies, such as smart lighting and smart rubbish bins. Adelaide has led the way in this activity, with the Adelaide City Council and State Government working with Cisco to conduct smart lighting and smart parking pilot programs that make use of their AdelaideFree wi-fi network (DSD, 2014; DSD, 2015; interview - City Official). Recently, the ACT government has shown interest in using its CBRfree wi-fi network as the base infrastructure for smart parking (ACT Govt, 2015). However, it is the use of public wi-fi as a tool to gather network metadata to inform urban infrastructure and service planning that is the focus of this paper.

City governments have become sensitised to the potential value of network metadata as both the volume of network users and the population with wi-fi equipped mobile devices has grown. AdelaideFree had over 6 million log-ins in 2016, while four in five Australians now have a smart phone (Auhl, 2017; Deloitte, 
2016). Logged-in users generate both location and web-usage data that can be captured by network operators, while wi-fi enabled devices (regardless of whether they are logged into a network) broadcast a beacon to wi-fi access points (APs) that generate location data which may also be captured. The value of this data to inform everything from traffic management to homeless services is becoming increasingly clear. As one city official recently told us, public wi-fi is an "essential urban infrastructure now ...[and] ...from a city perspective, the data analysis that we can capture from the access points is hugely valuable...". Another official noted "if councils only think about just providing wi-fi [access], they're missing the opportunities that that can provide you with data". "There's no doubt that data is the new currency", according to another official we interviewed.

However, such plans are frustrated by the dominant public-private partnership (PPP) business model that has been adopted for network provision. As we discuss below, the contractual and regulatory terms typically governing network provision can limit data availability for municipal network owners. Such tensions might well be expected in this rapidly evolving technological and governance environment. However, with the increasing appearance of municipal 'smart city' strategies driven by local authorities and higher governments (DPM\&C, 2016) and supported by vendors and consultants eyeing off an estimated $\$ 120$ billion market in loT services in Australia alone (KPMG, 2016; Nokia, 2016; Arup, 2010), it is timely to reflect on what we can learn from the public wi-fi rollout. The key point to make here is that the field of telecommunications is relatively new territory for local authorities. Investment in local wireless networks engages national and international policies and protocols, the negotiation of a complicated regulatory environment, and complex decisions about technology platforms, procurement and data use. The diversity of the local jurisdiction in Australia suggests an uneven distribution of knowledge and decision-making capacity, although, as we have argued elsewhere (McShane et al., 2014), following market liberalisation in the early 1990s some regional cities and shires adopted innovative strategies to respond to local telecommunication deficiencies. The relentless futurism that shapes and suffuses smart city discourse (Urry, 2016) may mask lessons that can be learnt from earlier forays in this area.

\section{Theoretical Position}

This paper is framed by the theoretical insights and literature associated with critical infrastructure studies. This body of work, which extends over at least four decades, aims to 'unblackbox' infrastructure, exposing the normative underpinnings, social imaginaries and power relations that shape infrastructure investment. Building on the foundational work of scholars such as Hughes (1983) on energy networks, and Star and colleagues (Star, 1999; Bowker and Star, 1999) on information systems, recent critical infrastructure scholarship includes work in media studies, cultural studies and the digital humanities (cf. Parks and Starosielski, 2015; Peters, 2015). This body of work looks beyond the political economy of infrastructure (Dodson, 2009) to theorise that the experience of infrastructure is a major element in the culture of late modernity. More than two decades ago, Williams (1993, p. 381) argued that infrastructure is "the outstanding feature of the modern cultural landscape". The subsequent emergence of the mobile phone as increasingly ubiquitous personal infrastructure, with its convergence of communication, computational and locational capacities, surely strengthens Williams' argument.

The research informing this paper, funded by the Australian Research Council (DP150102818), aims to investigate investment by Australian municipal and state governments in wi-fi networks from multiple perspectives: policy rationales, technical platforms, business models and user experience. This paper draws on a series of field interviews with local government officials, field observation, and analysis of policy and publicity documents and media reportage associated with networks in several Australian cities. As the paper details, a present limitation of this research is the availability of network usage data from the local and state authorities controlling our study sites. Commercial reasons are commonly advanced as a rationale for withholding this data, a rationale that also extends to restricting access to elements of the public-private contracts that underpin wi-fi provisioning. While this presents as a research problem for our project, it raises larger questions of public interest and open government.

\section{Setting the Context}

Public wi-fi is the first significant engagement of Australian city governments in wireless infrastructure policy and practice. We argue that analysis of public wi-fi investment provides a critical and grounded perspective on the 'smart city' city ambitions of governments. Defining a 'smart city' is complex, requiring first an acknowledgement of the term's historicity. Although it has been recently elevated from a large cluster of rivals (ubiquitous city, digital city, intelligent city, knowledge city and so on (Cocchia, 2014)), the reification of 'smart' and its association with networks connects it to the earliest thinking about the city as a circulatory system, a metaphor taken from Harvey's 1628 discovery of blood circulation (Williams, 1993). According to McNeill (2015), 'smart city' has four overlapping meanings focused on 
connectivity, data, infrastructure, and resource consumption/sustainability. The Centre for Cities (2014) distinguishes between bureaucratic, data-driven and citizen perspectives. It is beyond the scope of this paper to canvass the extensive literature on this point (see Cocchia, 2014 for a systematic review), but for our purposes a 'smart city' is characterised by the extensive deployment of digital communication technologies and the use of network data in urban governance. In Clarke and Brooks' (2015, p. 2) view, smart city initiatives involve:

...us[ing] operational technologies, civic technologies, the Internet of Things (IoT) and the $3^{\text {rd }}$ Platform (cloud, social, mobile, and big data/analytics) to understand the workings of a city at a level of unprecedented detail, provide new and innovative services to citizens and local businesses, and change or nudge the collective behavior of government workers, local business, and residents to achieve broad social, environmental, and financial outcomes.

Much of the Australian-focused literature in the smart city field engages with this topic at an international register. This acknowledges the global dimensions of neo-liberal urban governance (as the underpinning logic of partnerships, mobile capital, and inter-city competition) and of technology markets. This paper contributes to an emergent body of empirical research on how the smart city concept is conceptualised and operationalised in Australia. Our work is directed by a case-study methodology in focusing on a selection of public wi-fi networks provided by local and state governments (the latter funding networks in several cities and towns within their jurisdiction), Flyvbjerg (2006) argues against a singular conception of the 'case study': in his schema, our field sites are an "information-oriented selection", designed to maximise the utility of information from small samples, and undertaken (drawing on Flyvbjerg's classic defence of the methodology) in the hope of learning something rather than proving something. Thus, while we are cautious about generalising from our field research, consistent findings have emerged regarding the deployment and use of public wi-fi at municipal level in Australia that complicate some of the smart city rhetoric and policy aspirations.

Barns et al.'s (2017) recent discussion of the challenges that digital infrastructure poses for urban governance provides a useful context for our focus on one form of that infrastructure - public wi-fi. Barns et al. argue that recent Australian public policy in the digital infrastructure sphere has evolved from a conventional engineering approach, concerned with technical, cost and project management dimensions (with the National Broadband Network an example), to focus more on the role of government in enabling data-driven smart city services and real-time urban management. The current policy model underpinning Australian and international developments in urban governance accepts that while public authorities are the custodians of valuable data, they lack the institutional capability to design and deliver smart urban governance. The particular characteristics of smart city government, often involving autonomous, data-driven real-time or predictive decisions, not only cede infrastructure provision to major private corporations (consistent with neo-liberal public-private-partnership arrangements) but important aspects of governance itself. Barns et al. (2017, p. 25) cite a claim by Arup, a major player in this field, that a benefit of smart city technologies is the "reinvention of governance", an echo, we observe, of Osborne and Gaebler's (1992) famous "reinventing government" dictum that urged sluggish public authorities to embrace the "entrepreneurial spirit".

Barns et al. (2017) identify two related challenges facing city governments in implementing smart city initiatives: (1) the fragmentation of the local jurisdiction, and the hollowing out of governmental capability and 'splintering' of infrastructure provision through privatisation; and (2) corporate capture by global smart city vendors, resulting in technological lock-in and a susceptibility to what Morozov (2013) calls "technological solutionism" - the recasting of complex phenomena as neatly defined problems with computable solutions (also see McNeill, 2015). Other analysts are more optimistic on questions of technology choice, the inter-operability of systems, and the willingness of local authorities to engage citizen know-how through open data and hackathons. Richterich (2017), for example, argues that the "open enough" quality of many proprietary systems positions them not simply as a corporate asset but as a "resource and opportunity" for citizens.

Whereas these commentators point to challenges that public authorities must confront in their transition to 'smart' governance, some analysts are more strident in their criticism of the smart city agenda, pointing to contradictions between promises that smart technologies will promote efficient resource use and environmental sustainability, and the ruthless socio-environmental cycle that envelops these technologies. Kaika (2017), for example, illustrates the simplification of such complex policy and ethical dilemmas, and sharpens the focus of our paper, by describing TreeWiFi, a birdhouse developed by a Dutch designer with an environmental sensor that glows green and provides free public wi-fi when air quality is high. Where the designer sought to induce an affective response and generate insights and debate on air pollution through the device, the techno-optimism undergirding much smart city narrative 
was displayed in newspaper reportage, with one headline chirping: "Can 'smart' birdhouses help improve air quality in Amsterdam?" (Kaika, 2017, p. 90).

Our concern is to examine public wi-fi as an operational and, in many cases, a pioneering element of the smart city in Australia, to understand what light this empirical example can shed on wider smart city ambitions. In the following section, we draw on our field research on the roll-out of public wi-fi, and analysis of a range of policy and research literature, to identify two barriers to these ambitions.

\section{Barriers to Smart City Ambitions}

\section{Local Authority Procurement Decisions}

Public wi-fi networks deployed by state and municipal governments in Australia have been underpinned by a range of different business models. In their Public Wi-Fi Implementation Guidelines, the Municipal Association of Victoria (MAV) Technology division (2015), point to three primary models: end-to-endownership where public wi-fi is fully owned and operated by council (most often done by leveraging existing infrastructure, such as expanding the footprint of an existing library network into surrounding outdoor spaces); discrete ownership, where Council performs part of the service and a service provider the rest (for instance, Council purchases wi-fi APs and utilises spare capacity on the corporate network for backhaul while a third party configures and supports the access points); and Public-PrivatePartnership (PPP), where the service is delivered through a partnership between government and private service providers. The PPP model has proven dominant over the past five years, particularly in major urban centres. For instance, during this time PPP contracts have been signed by state and local governments and private telecommunications companies (telcos) in Tasmania, the ACT, Adelaide, Victoria (covering Melbourne, Ballarat and Bendigo), Brisbane and Perth.

While PPPs have emerged as a common model for infrastructure provision in the past three decades (Hodge, 2005), governments are in part drawn to the PPP model for deploying public wi-fi because they can bring more than simply financial incentives to the negotiating table with telcos. The technical regulation of wi-fi that limits its power and range (explained below) requires public wi-fi APs to be physically located every 50-100 metres in areas planned for blanket meshed coverage (a configuration now preferred over single-point 'hotspots' given the always-connected nature of mobile devices and corresponding ubiquitous connectivity demands of the public). This requirement can be accommodated by local and state governments that have an extensive and widely dispersed set of infrastructure on which to mount APs, such as light poles, bus shelters and traffic lights. Some of this infrastructure is even equipped with existing electrical power and backhaul capabilities. Of the potential telco partners, it is only Telstra that has been able to contribute substantially to physical infrastructure resources required by public wi-fi. In its PPP negotiation, Telstra has leveraged access to its own dispersed set of infrastructure, the public telephone network, recently winning contracts with the Brisbane City Council and the Tasmanian state government (Quirk, 2015; Ferguson, 2015).

Municipal and state governments have also been keen to work with telco partners because of some degree of uncertainty around the regulatory parameters that apply to public wi-fi. Wi-fi itself is subject to very little technical regulation. It makes use of spectrum originally set aside for "Industrial, Scientific and Medical" (ISM) activity which does not require an individual licence to access. The conditions of access that do exist are imposed by setting the technical standards to which transmitting and receiving equipment must conform under a 'class licence' (see ACMA, 2016b). Where networks are for domestic and private use, wi-fi regulation is clearly limited to these technical aspects. However, where wi-fi is deployed for public access it may in some circumstances fall under the definition of a telecommunications service articulated in the Telecommunications Act (1997), making it subject to more rules, including a requirement for network operators to hold a Carrier licence and to comply with dataretention provisions (OCAC, 2015, S.7; MAV Technology, 2015; ACMA, 2016b; ACMA, 2017). Uncertainty around those circumstances has encouraged governments to enter PPPs, with Expression of Interest (EOI) calls commonly making a Carrier licence mandatory (cf. DSG, 2015b; DSDBI, 2014).

In meeting smart city objectives related to broadband access, the PPP model has worked well. However, it is in seeking to move from the provision of public wi-fi as a service to public wi-fi as data gathering tool to inform urban infrastructure and service planning that has proven more problematic in PPP deployments. In some cases, the information gathering smart city objective has emerged after contracts for public wi-fi provision have been signed. In these cases, contracts can be changed to accommodate the transfer of network data from the telco to the government but this will carry costs. Commercial parties now clearly understand the value of network data themselves. As one council official noted "[w]e now realise the value of the data that these companies are getting, and we're missing out on that". In 
responding to a question about access to location data to map pedestrian flows, one city official told us "unfortunately, we can't get access to that level of data. I'm sure [the telco] would love to sell that to us, but we don't want to pay for that... we couldn't justify the costs. Yeah, it's a quarter of a million dollars a year for that, just accessing that data and licensing it, so it's a waste of money, we can't do that... [although there are] lots of interesting ways we could use that data". With most public wi-fi PPP contracts running from three to five years, some governments will have some time to wait before being able to address data access concerns. Indeed, given the pace with which information and infrastructure demands change in the smart city technologies area, the experience of public wi-fi PPP is instructive.

Even where telcos and municipal or state governments come to an arrangement about data access, there can be issues around transferring data while meeting the privacy provisions of the federal Telecommunications Act (1997) and Australian Privacy Principles established in the Privacy Act (1988). As data collectors, the telco partners are required to ensure any data they transfer is not and cannot be transformed into personally identifiable information. While adhering to these regulations is important, one city official told use that in being "hyper-sensitive to risk" their telco partner could not provide data at an appropriately refined level to make urban management decisions. Associated with this problem, without access to 'raw data' from telcos to explore in an open manner, government partners find it difficult to clarify just what their information needs are. Given these issues, one city official noted they would explore non-PPP options when the contract came up for renewal. This official recommended other councils contemplating PPP provision to "think about how you can access the data or get the data from your providers, because it can be a game changer".

An extended issue with regards to the public value that can be realised from public wi-fi network data provided through PPPs relates to open data initiatives. While Findlay (2015) argues that "governments across Australia have pretty much universally adopted good, strong policies on the release of data", the release of usable public wi-fi data is limited, even where governments have had the best of intentions. When the Lord Mayor of Brisbane announced that the public wi-fi contract had been awarded to Telstra in 2015, he indicated that "once up-and-running, information about wi-fi usage in the new CBD hot-spot would be made available under Council's Open Data initiative" (Quirk, 2015). This Open Data project would "see digital information sets, including usage patterns and volumes, made accessible to the public, while preserving all privacy for users"-a dataset that council expected might be used by startup enterprises (Quirk, 2015). But this has seemingly proved difficult to achieve, and to date the data available as part of the Open Data initiative is simply a list of access point locations (BCC, 2016). We are yet to hear back from the council as to whether particular contractual arrangements have impeded the public release of data, but when we have asked other city governments about open data provisions in relation to public wi-fi PPPs we have not received an encouraging response. When we asked one representative about the possibility that the private operator might release usage data for research purposes, our interview transcript records the response as "No...(laughter)".

Getting access to data from public wi-fi networks is only one impediment to implementing smart urban management. Our research suggests that, even with data in hand, local governments may find that they do not currently have the human resource capabilities to manage, analyse and transform this data into urban infrastructure and service planning decisions.

\section{Local Human Resource Limitations}

Analysis of the ICT capabilities of the Australian local government sector has focused on individual skills, framed in terms of digital literacy, while paying limited attention to the broader competence for IT planning, which is seen as critical for strategic decision-making in smart city governance ( $\mathrm{Ni}$ and Chen, 2016). Local government workforce surveys paint a somewhat confusing picture in this area. A Government Skills Australia (2015) survey indicated that $60 \%$ of LGA respondents nominated information and communications as a priority training area. However, this area is not addressed directly or substantially in a national workforce strategy covering the period 2013-2020, ironically titled FutureProofing Local Government (Zivkovic and Kats, 2013). A sample of training courses offered to elected officials across Australia revealed no content relating to any aspects of digital urban governance (Davy and Brands, 2012).

Clarke and Brooks (2015), who are associated with market analysts IDC, incorporate IT competence within their broader modelling of a smart city "maturityscape", a self-analysis tool that the authors argue will enable city governments to "assess their current situation and determine the critical capabilities required to develop a Smart City". Their model maps "smart city' investment maturity from "ad-hoc" or tactical and uncoordinated decision-making, through to "optimized" or a "sustainable, citywide platform providing agile innovation, strategy, IT and governance for integrated system of systems" (Clarke and 
Brooks, 2015, p. 1). This expansive view seems calibrated on large cities governed through a commandand-control ethos that is depicted in the much-reproduced image of IBM's Rio di Janeiro control centre (Singer, 2012). This image is hardly representative of Australia's fragmented local jurisdiction, which is dominated by small cities and towns. The image also seems remote from the mundane and sometimes messy service environment of Australian local governments. For example, in 2017 the peak body Municipal Association of Victoria set up a Local Government Digital Transformation Task Force. A survey of MAV members identified six "pressure points" which have guided the task force's medium term priorities: animal registration, customer transactions, infringements, disabled parking permits, waste management, and planning and building (Ballie, 2016). In this setting, digital transformation is not so much focused on abstractions such as IDC's "system of a systems" but with applying ICTs and digital networks to efficiently manage operational areas with intensive levels of citizen and customer engagement.

Tapping the potential for capturing and operationalising big data through city-managed networks to understand the 'workings of the city' seems overwhelming for some LGAs. One city official we interviewed noted that there was a tendency to "cling to" old models of citizen data collection, such as surveys. While these methods may have their limitations, he made it clear that new 'big data' digital collection strategies can lack immediate utility:

"I'm still trying to work out what happens if I have that [traffic data] for every day, every

hour, every minute... we're realising ... it's nice to have that stuff, but actually what does

it mean and can we actually do the quantum leap that we need to do".

In accepting that telecommunications and digital data were emergent concerns for city governments, this official candidly admitted that his council was not alone in being stretched by this, noting "I think we're all scrambling in government to understand how to connect...". In this light, he noted that there will be demand for new positions in council to try and interpret the data from public wi-fi and other smart city infrastructure: "So, in terms of human planning on human resources I think I need data analysts in my team, but to do that I actually need to know where to get the data from and I'm still trying to work that out".

In such a setting, local administrations with limited expertise and resources to guide planning and strategic decision-making in smart governance may be susceptible to off-the-shelf solutions offered by vendor companies, and perhaps risk data and technology capture, as Barns et al. (2017) observe. However, our research on local government involvement in public wi-fi, suggests a knowledge deficit that is not restricted to less well-resourced local authorities, but endemic to standard models of policy formation and implementation across all levels of government. At the centre of this problem are the limitations of standard economic models for public infrastructure investment, such as cost-benefit analysis. These ex-ante models fail to capture the post-hoc innovation or user-generated value of digital networks, leading to sub-optimal or poorly articulated investment choices, and constrained evaluation of network uses and benefits. Without seeking to overstate the argument, the exemplar here is the internet itself: the initial sponsors of investment in a decentralised communications network designed for security purposes in a Cold War context could hardly have predicted the ensuing social and economic benefits (Ryan, 2013). The key point, though, is that the openness and public ownership of the internet encouraged experimentation and adaptation. A corporate-driven smart city model may leave little room for the participation of local officials and citizens, privatising data obtained from public networks and discouraging access to distributed knowledge and user-generated social innovation (Bar and Borrus, 1998).

\section{Conclusion}

Public wi-fi has emerged as one of the first substantial smart city initiatives in Australia, with investment by municipal and state governments over the past five years producing operational networks in almost all capital city CBDs, many suburban centres and regional cities, and even some smaller towns. The initial rationales for public wi-fi investment centred on the provision of enhanced local communication services for citizens and visitors. However, city governments have increasingly recognised the potential for public wi-fi to be used in broader aspects of urban governance. While this includes using public wi-fi as a base infrastructure to provide backhaul connectivity to control smart city loT technologies, as has been trialed in Adelaide, it is the use of spatial and other data from public wi-fi users and wi-fi enabled devices to inform smarter urban infrastructure and service planning that has been the focus of this paper.

In this paper we argue that realising the potential of public wi-fi to inform smarter city government has not been straightforward. This is perhaps not surprising given that telecommunications is essentially a new field of activity for city governments - having always been the policy domain of the federal government and a provisioning concern, at least since the introduction of market liberalisation in the 
early 1990s, of the commercial sector. Indeed, the one of the central impediments to realising public wifi's smart city urban governance potential is influenced by this history. City governments have tended to rely on the commercial telco sector's technical and regulatory position to deliver public wi-fi through Public-Private-Partnership arrangements. While this model has been effective in developing networks that provide city residents and visitors broadband access, it has generally not been conducive to the effective transfer of data from the telcos that operate the networks to the city government partners who wish to use it to inform urban governance.

Our examination of public wi-fi has highlighted a second impediment to the implementation of smart city urban management - city government human resource capacity. Our research suggests that, even with data in hand, local governments may find that they do not currently have the capacity to manage, analyse and transform this data into urban infrastructure and service planning decisions. A danger of both a reliance on PPPs for wireless network delivery and limited municipal government urban data collection and analytics resources is that control over urban governance will swing too far towards the commercial purveyors of 'smart city' solutions.

\section{References}

ACCC, 2016. Competition in evolving communications markets. Canberra: Australian Competition and Consumer Commission.

ACMA, 2016a. Public Wi-Fi hotspots: food for thought! Sydney: Australian Communications and Media Authority.

ACMA, 2016b. Wireless LANs in the $2.4 \mathrm{GHz}$ band FAQ. Sydney: Australian Communications and Media Authority.

ACMA, 2017. Wireless LANs: licensing requirements. Sydney: Australian Communications and Media Authority.

ACT Govt, 2015. Smart Parking - transforming parking in the ACT Discussion Paper. Canberra: Chief Minister, Treasury and Economic Development Directorate Policy and Cabinet Division, Government Reform Branch Smart City Team.

Arup, 2010. Smart Cities: Transforming the 21st century city via the creative use of technology. London: Arup.

Auhl, P., 2017. Case studies from leading Australian cities - Adelaide. Australian Smart Communities Conference, 29-31 May 2017 Adelaide.

Ballie, K., 2016. Local Government Digital Transformation Task Force - Challenges \& Priorities. MAV Technology National Conference - 2020 Vision, 10-12 August 2016 Melbourne.

Bar, F. and Borrus, M., 1998. The Path Not Yet Taken: User Driven Innovation and US Telecommunications Policy. Fourth Annual Consortium for Research on Telecommunications Policy and Strategy Conference, 5-6 June 1998 Ann Arbor, Michigan.

Barns, S., Cosgrave, E., Acuto, M., and McNeill, D., 2017. Digital Infrastructures and Urban Governance. Urban Policy and Research, 351, 20-31.

BCC, 2016. Wireless hotspot sites - Libraries and Parks. Brisbane: Brisbane City Council.

Bowker, G.C. and Star, S.L., 1999. Sorting things out: classification and its consequences. Cambridge: MIT Press.

Centre for Cities, 2014. Smart Cities. London: Centre for Cities.

Clarke, R.Y. and Brooks, A., 2015. IDC MaturityScape: Smart City. Framingham: International Data Corporation.

Cocchia, A., 2014. Smart and Digital City: A Systematic Literature Review. In: R.P. Dameri and C. Rosenthal-Sabroux, eds. Smart City How to Create Public and Economic Value with High Technology in Urban Space. Springer, Cham: Springer International Publishing.

Commonwealth of Australia, 1988. Privacy Act. Commonwealth of Australia.

Commonwealth of Australia, 1997. Telecommunications Act. Commonwealth of Australia. 
Davy, S. and Brands, J., 2012. A National Review of Training and Development for Local Government Councillors. Sydney: Australian Centre of Excellence for Local Government.

Deloitte, 2016. Mobile Consumer Survey 2016. Sydney: Deloitte Touche Tohmatsu Limited.

Dodson, J., 2009. The 'Infrastructure Turn' in Australian Metropolitan Spatial Planning. International Planning Studies, 14 (2), 109-123.

DPM\&C, 2016. Smart Cities Plan. Canberra: Department of Prime Minister and Cabinet.

DSD, 2014. State Govt, Adelaide City plug in to Internet of Things Innovation Hub. Adelaide: Department of State Development, Government of South Australia.

DSD, 2015. Adelaide named Australia's first 'Lighthouse City' for innovation. Adelaide: Department of State Development, Government of South Australia.

DSG, 2015. Request for Proposal. Hobart: Department of State Growth, Tasmanian Government..

DSDBI, 2014. Invitation for Expressions of Interest EOI. - Victorian Public Wi-Fi Service - Central Melbourne. Melbourne: Department of State Development, Business and Innovation Victorian Government.

Ferguson, M., 2015. Free Wi-Fi. Minister for Information Technology and Innovation. Hobart: Tasmanian Government.

Findlay, C., 2015. An insider's view of the state of open data in Australia. The Walkly Foundation Online, 5 July.

Flyvbjerg, B., 2006. Five Misunderstandings About Case-Study Research. Qualitative Inquiry, 12 (2), 219-245.

Government Skills Australia. 2015. 2015 Environmental Scan - Local Government. Adelaide: Government Skills Australia.

Hodge, G.A., 2005. Public-private partnerships: the Australasian experience with physical infrastructure. In: G.A. Hodge and C. Greve, eds. The challenge of public-private partnerships : learning from international experience. Cheltenham: Edward Elgar, 305-331.

Hughes, T.P., 1983. Networks of power: electrification in Western society, 1800-1930. Baltimore: Johns Hopkins University Press.

Humphry, J., 2014. Homeless and Connected: Mobile phones and the Internet in the lives of homeless Australians. Sydney: Australian Communications Consumer Action Network and University of Sydney.

Kaika, M., 2017. 'Don't call me resilient again!': the New Urban Agenda as immunology ... or ... what happens when communities refuse to be vaccinated with 'smart cities' and indicators. Environment and Urbanization, 29 (1), 89-102.

KPMG, 2016. Creating Connections: IoT Foundations for Smart Cities. Sydney: KPMG.

Lambert, A., McQuire, S. and Papastergiadis, N., 2013. Free Wi-Fi and Public Space: The state of Australian public initiatives. Melbourne: Institute for a Broadband-Enabled Society.

MAV Technology, 2015. Public wifi implementation guidelines. Melbourne: Charlie Mac \& Associates for the Municipal Association of Victoria - Technology Division.

McNeill, D., 2015. Global firms and smart technologies: IBM and the reduction of cities. Transactions of the Institute of British Geographers, 40 (4), 562-574.

McShane, I., Gregory, M. and Wilson, C.K., 2016. Practicing Safe Public Wi-Fi: Assessing and Managing Data-Security Risks. Melbourne: RMIT Centre for Urban Research \& auDA Foundation.

McShane, I., Wilson, C.K. and Meredyth, D., 2014. Broadband as Civic Infrastructure - The Australian Case. Media International Australia, 151, 127-136.

Morozov, E., 2013. To save everything, click here: smart machines, dumb humans, and the myth of tecnological perfectionism. New York: Perseus Books. 
Ni, A.Y. and Chen, Y.C., 2016. A Conceptual Model of Information Technology Competence for Public Managers: Designing Relevant MPA Curricula for Effective Public Service. Journal of Public Affairs Education, 22 (2), 193-212.

Nokia, 2016. A New World of Cities and the Future of Australia. Espoo, Finland: Nokia.

OCAC, 2015. Data retention: frequently asked questions for industry. Canberra: Office of the Communications Access Co-ordinator.

Osborne, D.E. and Gaebler, T., 1992. Reinventing government: how the entrepreneurial spirit is transforming the public sector. New York: Plume.

Parks, L.D. and Starosielski, N., eds., 2015. Signal traffic: critical studies of media infrastructures. Urbana: University of Illinois Press.

Peters, J.D., 2015. The marvelous clouds: toward a philosophy of elemental media. Chicago: University of Chicago Press.

Picco-Schwendener, A. and Cantoni, L., 2015. Tourists and Municipal Wi-Fi Networks: The Case of Lugano Switzerland. In: I. Tussyadiah and A. Inversini eds. Information and Communication Technologies in Tourism 2015: Proceedings of the International Conference, 3-6 February 2015 Lugano, Switzerland. Cham: Springer International Publishing, 565-578.

Productivity Commission, 2017. Telecommunications universal service obligation: inquiry report. Canberra: Productivity Commission.

Quirk, G., 2015, Lord Mayor announces next step in smart city Wi-Fi plan Media Release. Brisbane: Lord Mayor of Brisbane, Graham Quirk.

Rennie, E., Hogan, E., Gregory, R., Crouch, A., Wright, A. and Thomas, J., 2016. Internet on the outstation: The digital divide and remote Aboriginal communities. Amsterdam: Institute of Network Cultures.

Richterich, A., 2017. Hacking events. Convergence, 26 May 2017, 1-27.

Ryan, J., 2013. A history of the Internet and the digital future. London: Reaktion Books.

Singer, N., 2012. Mission Control, Built for Cities. New York Times, 3 March, Online edition.

Star, S.L., 1999. The ethnography of infrastructure. American behavioral scientist, 43 (3), 377-391.

Urry, J., 2016. What is the future? Cambridge: Polity.

Williams, R., 1993. Cultural Origins and Environmental Implications of Large Technological Systems. Science in Context, 6 (2), 377-403.

Wilson, C.K. and McShane, I., 2017. Public WiFi Initiatives. Public WiFi in Australia, Available: https://publicwifiaustralia.com/.

Zivkovic, A. and Kats, A., 2013. Future-proofing local government: national workforce strategy 20132020. Sydney: Australian Centre of Excellence for Local Government. 